\title{
Helicobacter Pylori Negative Extra-nodal Marginal Zone B Cell Lymphoma of Mucosa Associated Lymphoid Tissue (MALT) Type Following Roux-en-Y Gastric Bypass (RYGB)
}

Zachary Eagle ${ }^{1}$, Francis Essien ${ }^{2}$, Kimberly Zibert ${ }^{3}$, Charles Miller ${ }^{3}$, Rina Eden ${ }^{2}$, and Ross Pinson $^{1}$

${ }^{1}$ Keesler AFB 81st MDG

${ }^{2}$ Keesler Air Force Base

${ }^{3}$ Brooke Army Medical Center

July 15, 2021

\begin{abstract}
Gastric MALT lymphoma is a common type of non-Hodgkin's lymphoma that has the potential for cure in patients found to have concomitant Helicobacter pylori infection.1,2 This case report explores the evaluation, diagnosis, and treatment of H. pylori negative MALT lymphoma in a patient with a history of a RYGB.
\end{abstract}

Title: Helicobacter Pylori Negative Extranodal Marginal Zone B Cell Lymphoma of Mucosa Associated Lymphoid Tissue (MALT) Type Following Roux-en-Y Gastric Bypass (RYGB)

Authors: Zachary R Eagle $\mathrm{MD}^{1}$; Francis Essien $\mathrm{DO}^{1}$; Kimberly Zibert $\mathrm{DO}^{2}$; Charles Miller $\mathrm{MD}^{2}$; Rina Eden $\mathrm{DO}^{3}$; Ross Pinson $\mathrm{MD}^{1,4}$

Author Affiliations:

${ }^{1}$ Keesler Air Force Base, MS; Keesler Medical Center, Department of Internal Medicine

${ }^{2}$ San Antonio Medical Center; Department of Internal Medicine, Division of Gastroenterology

${ }^{3}$ Keesler Air Force Base, MS; Keesler Medical Center, Department of Internal Medicine, Division of Pathology

${ }^{4}$ Keesler Air Force Base, MS; Keesler Medical Center, Department of Internal Medicine, Division of Gastroenterology

Corresponding Author: Zachary Eagle

Zachary Eagle

Keesler Medical Center

301 Fisher Street

Keesler AFB 39534 Email:zachary.r.eagle2.mil@mail.mil

Abstract: 
Gastric MALT lymphoma is a common type of non-Hodgkin's lymphoma that has the potential for cure in patients found to have concomitant Helicobacter pylori infection. ${ }^{1,2}$ This case report explores the evaluation, diagnosis, and treatment of $H$. pylori negative MALT lymphoma in a patient with a history of a RYGB.

\section{Key clinical message:}

In patients with gastric MALT lymphoma and a RYGB, surveillance of both the gastric pouch and remnant should be performed as it can occur in both locations despite anatomical separation.

\section{Introduction}

Extra-nodal marginal zone lymphoma (MZL) of MALT type compose $7 \%$ of all non-Hodgkin's lymphomas. ${ }^{1}$ Approximately one-third present as a primary gastric lymphoma; $90 \%$ are associated with Helicobacter pylori (H. pylori ). ${ }^{1,2}$ The etiology of $H$. pylori negative lymphoma of MALT type remain controversial. Differentiating $H$. pylori negative from $H$. pylori lymphoma of MALT type is important in regards to treatment and prognosis. The incidence of primary MALT lymphoma of the gastric remnant or gastric pouch is not well defined but appears to be quite rare with less than 35 cases reported worldwide. In this case report, we discuss the suspected etiologies, diagnosis, treatment, and outcome of a 36-year-old female found to have $H$. pylori negative gastric lymphoma of MALT type. The case is further complicated by history of Roux-en-Y gastric bypass (RYGB) for treatment of refractory gastroesophageal reflux disease (GERD).

\section{Case Description}

A 36-year-old African American female with history of systemic sclerosis and refractory GERD status post RYGB presented to her primary care provider with complaints of daily nausea, non-bloody emesis, dysphagia, and abdominal pain refractory to all medical therapy. Patient had undergone endoscopic evaluation multiple times for this complaint initially limited to the gastric pouch secondary to surgical anatomy with no abnormalities noted. Laboratory analysis was notable for normal CBC, CMP, negative serologic and stool Helicobacter pylori antigen testing. The patient was referred back to gastroenterology for repeat upper endoscopic evaluation. The gastric pouch was notable for diffuse edema, punctate erythema, and friability (Figure 1) . Biopsies demonstrating chronic gastritis with extra-nodal marginal zone lymphoma of MALT type (Figure 2, 3). A single balloon enteroscopy was then performed for evaluation with biopsies obtained of the gastric remnant. Similar gross findings were seen in the gastric remnant, however, biopsies showed dense lymphoid infiltrate consistent with MALT lymphoma. All biopsies were negative for $H$. pylori by immunohistochemical stains. Previous biopsies prior to RYGB surgery were reviewed and confirmed to be negative for $\mathrm{H}$ pylori infection as were serologic and stool antigen tests.

The patient was diagnosed with $\mathrm{H}$ pylori negative gastric MALT lymphoma, Lugano stage I, Ann Arbor IE. The case was discussed with a multi-disciplinary team including medical and radiation oncology. After discussion with the patient, the decision was made to treat with rituximab given the risk of large field radiation and her underlying systemic sclerosis. Repeat endoscopy with biopsy after 4 weeks of treatment showed no appreciable gross or histologic changes. Having failed immunosuppressant therapy, patient was initiated on radiation therapy for a total dose of 30 Gy. On follow up symptoms had improved; repeat single balloon enteroscopy showed mucosal improvement. Biopsies were notable for focal atypical lymphoid infiltrate with monocytoid cytomorphology and focal lymphoepithelial lesion formation, compatible with focal, residual marginal zone lymphoma (partial histologic regression). The amount of atypical lymphoid infiltrate was too small for further assessment by immunohistochemistry. Repeat endoscopy was planned within the next three months but unfortunately with the advent of COVID patient was lost to follow up.

\section{Discussion}

Development of gastric MALT lymphoma appears to arise from two distinct pathways both involving dysregulation of nuclear factor kappa light chain enhancer of activated B-cells (NF-kB) activity. ${ }^{7}$ There is a B-Cell receptor (BCR) dependent NF-kB activation pathway and BCR-independent NF-kB activation pathway. ${ }^{7,8}$ BCR dependent NF-kB activation relies on persistent antigen stimulation which elicits inflammation and 
accelerated lymphoid proliferation through a polyclonal B-cell response..$^{7,9,10}$ This pathway is also recognized as an anti-microbial responsive lymphoid proliferation as when the stimulating antigen is removed, the inflammation and lymphoid proliferation resolves. ${ }^{11}$ The above mechanism is further supported by the effectiveness of eradication therapy in the treatment of $H$. pylori associated MALT lymphoma. Current literature suggests regression in up to $83 \%$ of $H$. pylori associated MALT lymphoma cases when given triple or quadruple therapy. ${ }^{12,13}$

Though uncommon, there are reports showing H. pylori negative MALT lymphoma similar to our case presented above. The predominating theory suggests a BCR-independent NF-kB activation pathway. Though there is a clear theory describing the pathway for lymphoid proliferation in $H$. pylori negative patients, the exact mechanism is yet to be determined and is likely multifactorial. One known etiology is a pseudo-negative H. pylori associated MALT lymphoma. In these patients, H. pylori testing is negative due to previous use of antibiotics, bismuth, proton pump inhibitors (PPIs), or a combination of the three despite active infection with $H$. pylori ${ }^{14}$ Some studies indicate t certain chromosomal translocations or tumor suppression gene mutations can cause constitutive lymphoid proliferation independent of a stimulating antigen. ${ }^{15}$ Multiple publications demonstrate a high incidence of translocation $(11 ; 18)(\mathrm{Q} 21 ; \mathrm{Q} 21)$ in $H$. pylori negative MALT lymphomas. ${ }^{7,16-18}$ These translocations cause a fusion of the N-terminus of the API2 gene to the C-terminus of the MALT1 gene and generates a functional API2-MALT1 fusion product which can constitutively activate the NF-kB pathway. ${ }^{19}$

Presence of the $\mathrm{t}(11 ; 18)(\mathrm{q} 21: \mathrm{q} 21)$ is seen in up to $30 \%$ of all gastric MALT lymphomas and are demonstrated in up to $68 \%$ that are at stage IIE or above. ${ }^{20}$ Unfortunately, the current available data has not closely evaluated the incidence of these translocations in patients with $H$. pylori negative gastric MALT lymphoma, though there are multiple studies that show expression of these translocations in up to $88 \%$ of these patients..$^{716-20}$ Regardless, the presence of $\mathrm{t}(11 ; 18)$ (q21:q21) can help guide therapy as they are only seen in approximately $3 \%$ of gastric MALT lymphomas that do respond to traditional $H$. pylori eradication therapy. ${ }^{20}$ Further studies noted that the presence of $\mathrm{t}(11 ; 18)(\mathrm{q} 21: \mathrm{q} 21)$ predicted poor response to alkylating agents (chlorambucil or cyclophosphamide) but was unable to predict the response to rituximab. ${ }^{21,22}$

Treatment of patients with $H$. pylori negative MALT lymphoma is complicated and differs depending upon the patient's comorbidities, staging, and the presence or absence of translocations. Current literature suggests using radiation therapy for patients with early stage (Lugano I/II) gastric MALT lymphoma without evidence of $\mathrm{H}$. pylori infection and reported clinical remission rates in up to $100 \%$ of patients. ${ }^{23,24}$ If radiation therapy fails or the patient is found to be at an advanced stage, treatment with immunotherapy (Rituxumab) can be trialed and has shown complete response in up to $46 \%$ of patients. ${ }^{22,25}$ Prior to discovery the of $\mathrm{H}$. pylori , targeted gastric resection was used to great therapeutic effect and long term survival. ${ }^{22,26}$ However, more recent studies suggest that organ conserving therapy presents no long-term disadvantages but spares the patient from permanent nutritional and metabolic derangements. ${ }^{27}$ For these reasons, surgical treatment of gastric MALT lymphoma is rarely pursued.

In the case above, testing for $\mathrm{t}(11 ; 18)(\mathrm{q} 21: \mathrm{q} 21)$ was negative. Rituximab was preferred over radiation therapy in our patient with history of systemic sclerosis but was ineffective.. She has shown endoscopic and histologic improvement with radiation therapy with 3 month repeat follow up endoscopy pending.

In conclusion, H. pylori negative gastric lymphoma of MALT type is an uncommon presentation of nonHodgkin lymphoma. Though the mechanism appears well researched, the specific etiology remains controversial. In patients with gastric lymphoma of MALT type, it is important to rule out $H$. pylori infection. If negative, further evaluation of the $\mathrm{t}(11 ; 18)(\mathrm{q} 21: \mathrm{q} 21)$ can help further guide therapy and predict patient outcomes. Lastly, MALT lymphoma in patients that have undergone Roux-en-Y gastric bypass is uncommon with less than 40 cases in the reported literature. Thus diagnosis can be delayed due to mimicking symptoms typically attributed to the bypass. Evaluation, not only of the gastric pouch, but also the gastric remnant should be performed in all at risk patients as gastric MALT lymphoma can occur in both locations despite post-operative anatomical separation. 
The authors confirm contribution to the paper as follows:

Study conception and design: Zachary R Eagle MD $^{1}$; Francis Essien $\mathbf{D O}^{\mathbf{1}}$; Kimberly Zibert DO$^{2}$; Charles Miller $\mathrm{MD}^{2}$; Rina Eden $\mathrm{DO}^{3}$; Ross Pinson $\mathrm{MD}^{1,4}$

Data collection Zachary R Eagle $\mathrm{MD}^{1}$; Rina Eden $\mathrm{DO}^{3}$; Ross Pinson MD ${ }^{1,4}$

Analysis and interpretation of results: Zachary R Eagle $\mathbf{M D}^{1}$; Kimberly Zibert $\mathbf{D O}^{2}$; Charles Miller $\mathrm{MD}^{2}$; Rina Eden $\mathrm{DO}^{3}$; Ross Pinson $\mathrm{MD}^{1,4}$

Draft manuscript preparation: Zachary R Eagle MD $^{\mathbf{1}}$; Francis Essien DO ${ }^{\mathbf{1}}$; Ross Pinson MD ${ }^{1,4}$

All authors discussed the results and contributed to the final manuscript.

Data sharing is not applicable to this article as no new data were created or analyzed in this study.

\section{References:}

1. Zucca E, Copie-Bergman C, Ricardi U, et al. Gastric marginal zone lymphoma of MALT type: ESMO Clinical Practice Guidelines for diagnosis, treatment and follow-up. Ann Oncol 2013; 24 Suppl 6:vi144.

2. Hu, Q., Zhang, Y., Zhang, X. et al. Gastric mucosa-associated lymphoid tissue lymphoma and Helicobacter pylori infection: a review of current diagnosis and management. Biomark Res 4, 15 (2016). https://doi.org/10.1186/s40364-016-0068-1

3. Sebagh M, Flejou JF, Potet F. Lymphoma of the gastric stump. J Clin Gastroenterol 1995;20:147-50.

4. Oshita H, Tanemura H, Kanno A et al. Malignant lymphoma occurring in the residual stomach following gastrectomy: plus discussion based on the literature in Japan. Gastric Cancer 2003; 6: 60-3.

5. Jawad, A., Bar, A.H., Merianos, D. et al. MALT Lymphoma of the Gastric Remnant After Roux-en-Y Gastric Bypass. J Gastrointest Canc 43, 194-197 (2012). https://doi.org/10.1007/s12029-012-9386-1

6. De Roover A, Detry O, de Leval L. Report of two cases of gastric cancer after bariatric surgery: lymphoma of the bypassed stomach and gastrointestinal stromal tumor (GIST) after vertical banded gastroplasty. Obes Surg. 2006;16:928-31.

7. Felipe Suarez, Olivier Lortholary, Olivier Hermine, Marc Lecuit; Infection-associated lymphomas derived from marginal zone B cells: a model of antigen-driven lymphoproliferation. Blood 2006; 107 (8): 3034-3044. doi: https://doi.org/10.1182/blood-2005-09-3679

8. Cavalli F, Isaacson PG, Gascoyne RD, Zucca E. MALT Lymphomas. Hematology (Am Soc Hematol Educ Program). 2001: 241-258.

9. Morse HC III, Kearney JF, Isaacson PG, Carroll M, Fredrickson TN, Jaffe ES. Cells of the marginal zone: origins, function and neoplasia. Leuk Res. 2001;25: 169-178.

10. Isaacson PG, Du MQ. MALT lymphoma: from morphology to molecules. Nat Rev Cancer. 2004;4: 644-653

11. Du M, Isaacson P. Gastric MALT lymphoma: from aetiology to treatment. Lancet Oncol. 2002;3: 97-104.

12. Wotherspoon AC, Doglioni C, Diss TC, et al. Regression of primary low-grade B-cell gastric lymphoma of mucosa-associated lymphoid tissue type after eradication of Helicobacter pylori. Lancet $1993 ; 342: 575$.

13. Kuo S., Yeh, K., Wu, M. et al. First-line antibiotic therapy in Helicobacter pylori-negative low-grade gastric mucosa-associated lymphoid tissue lymphoma. Sci Rep 7, 14333 (2017). https://doi.org/10.1038/s41598-017-14102-8.

14. Sung-Hsin , Kuo. "First-Line Antibiotic Therapy in Helicobacter Pylori-Negative LowGrade Gastric Mucosa-Associated Lymphoid Tissue Lymphoma." Nature, 30 Oct. 2017, www.nature.com/articles/s41598-017-14102-8.

15. Farinha P, Gascoyne RD. Molecular pathogenesis of mucosa-associated lymphoid tissue lymphoma. J Clin Oncol. 2005;23: 6370-6378.

16. Liu, H. et al . $\mathrm{T}(11 ; 18)$ is a marker for all stage gastric MALT lymphomas that will not respond to $\mathrm{H}$. pylori eradication. Gastroenterology. 122, 1286-1294 (2002). 
17. Liu, H. et al. Resistance of $\mathrm{t}(11 ; 18)$ positive gastric mucosa-associated lymphoid tissue lymphoma to Helicobacter pylori eradication therapy. Lancet. 357, 39-40 (2001).

18. Nakamura, T., Nakamura, S., Yonezumi, M., Seto, M. \& Yokoi, T. The t(11;18)(q21; q21) translocation in H. pylori-negative low-grade gastric MALT lymphoma. AmJ Gastroenterol. 95, 3314-3315 (2000).

19. Ruskoné-Fourmestraux A, Fischbach W, Aleman BMP, et al. EGILS consensus report. Gastric extranodal marginal zone B-cell lymphoma of MALT. Gut 2011;60:747-758.

20. Hongtao Ye, Hongxiang Liu, Markus Raderer, Andreas Chott, Agnes Ruskone-Fourmestraux, Andrew Wotherspoon, Martin J. S. Dyer, Shih-Sung Chuang, Ahmet Dogan, Peter G. Isaacson, Ming-Qing Du; High incidence of $\mathrm{t}(11 ; 18)$ (q21;q21) in Helicobacter pylori-negative gastric MALT lymphoma. Blood 2003; 101 (7): 2547-2550. doi: https://doi.org/10.1182/blood-2002-10-3167

21. Levy M, Copie-Bergman C, Gameiro C, et al. Prognostic value of translocation t(11;18) in tumoral response of low-grade gastric lymphoma of mucosa-associated lymphoid tissue type to oral chemotherapy. J Clin Oncol 2005;23:5061-6.

22. Martinelli G, Laszlo D, Ferreri AJ, et al. Clinical activity of rituximab in gastric marginal zone nonHodgkin's lymphoma resistant to or not eligible for anti-Helicobacter pylori therapy. J Clin Oncol 2005;23:1979-83.

23. Hitchcock $\mathrm{S}, \mathrm{Ng} \mathrm{AK}$, Fisher DC, et al. Treatment outcome of mucosa-associated lymphoid tissue/marginal zone non-Hodgkin's lymphoma. Int J Radiat Oncol Biol Phys 2002; 52:1058.

24. Tsang RW, Gospodarowicz MK, Pintilie M, et al. Localized mucosa-associated lymphoid tissue lymphoma treated with radiation therapy has excellent clinical outcome. J Clin Oncol 2003; 21:4157.

25. Martinelli G, Laszlo D, Ferreri AJ, et al. Clinical activity of rituximab in gastric marginal zone nonHodgkin's lymphoma resistant to or not eligible for anti-Helicobacter pylori therapy. J Clin Oncol 2005; 23:1979.

26. Gold, Douglas, Miller, Robert, Peterson, Ivy, et al. Radiotherapy for Malignancy in Patients with Scleroderma: The Mayo Experience. International Journal of Radiation Oncology. 2007: Vol 67, Issue 2, Pg:559-567

27. Koch P, del Valle F, Berdel WE, et al. Primary gastrointestinal non-Hodgkin's lymphoma: II. Combined surgical and conservative or conservative management only in localized gastric lymphoma - results of the prospective German Multicenter Study GIT NHL 01/92. J Clin Oncol 2001;19:3874-83

28. Vrieling C, de Jong D, Boot H, et al. Long-term results of stomach-conserving therapy in gastric MALT lymphoma. Radiother Oncol 2008;87:405-11

\section{Hosted file}

Figures.docx available at https://authorea.com/users/422167/articles/530477-helicobacterpylori-negative-extra-nodal-marginal-zone-b-cell-lymphoma-of-mucosa-associated-lymphoidtissue-malt-type-following-roux-en-y-gastric-bypass-rygb 